\title{
Knowledge, attitudes, and preventive practices toward the COVID-19 pandemic: an online survey among Bangladeshi residents
}

\author{
Satyajit Kundu ${ }^{1} \cdot$ Md. Hasan Al Banna ${ }^{2} \cdot$ Abu Sayeed $^{3}$ (D) Musammet Rasheda Begum ${ }^{4} \cdot$ Keith Brazendale $^{5}$. \\ M. Tasdik Hasan ${ }^{6}$. Sanjida Jahan Habiba ${ }^{7}$. Mohammad Tazrian Abid $^{7}$ • Md. Asaduzzaman Khan ${ }^{8}$. \\ Sukanta Chowdhury ${ }^{9} \cdot$ Tapos Kormoker $^{10} \cdot$ Ram Proshad $^{11,12} \cdot$ Md Shafiqul Islam Khan $^{2}$
}

Received: 31 July 2020 / Accepted: 10 July 2021

(C) Springer-Verlag GmbH Germany, part of Springer Nature 2021

\begin{abstract}
Aim The novel coronavirus (SARS-CoV-2) has rapidly infected people worldwide, leading to a massive public reaction. Peoples' knowledge, attitudes, and practices (KAP) toward COVID-19 are the most important for the control and prevention of the infectious disease pandemic. This study aimed to assess the knowledge, attitude, and preventive practices (KAP) toward the COVID-19 among Bangladeshi residents during the lockdown situation.

Subjects and methods An online-based cross-sectional survey was conducted among 1765 Bangladeshi adults through the social media networks of the authors.

Results The respondents were older than 18 years, with an average age of 24.88 years (SD 6.30). Approximately $15 \%$ of our participants received online training. The mean knowledge score was 14.49 (SD 1.8, range 0-17), and the overall correct response rate on this knowledge test was $85 \%$. Approximately $67.2 \%$ scored well (above the mean 4.5, range 1-5) regarding the practices. To avoid the infection, $96.6 \%$ wore masks outside the home, and $98.7 \%$ washed their hands with soap when they came back. COVID-19 knowledge score was significantly associated with a lower odds of (OR 0.87, 95\% CI 0.79-0.92) negative attitudes. Again, the awareness score was associated with a lower likelihood of (OR 0.94, 95\% CI 0.87-0.98) poor practices. Conclusion Online health education programs focusing on young people, housewives, and people with less education may potentially improve the attitudes and practices to control the COVID-19 pandemic in the long term in such a low-resource setting.
\end{abstract}

Keywords COVID-19 $\cdot$ Knowledge $\cdot$ Attitude $\cdot$ Practice $\cdot$ Bangladesh

Satyajit Kundu, Md. Hasan Al Banna and Abu Sayeed contributed equally to this study.

Abu Sayeed

shuvo.nfs.pstu@gmail.com

1 Department of Biochemistry and Food Analysis, Patuakhali Science and Technology University, Patuakhali 8602, Bangladesh

2 Department of Food Microbiology, Patuakhali Science and Technology University, Patuakhali 8602, Bangladesh

3 Department of Post-Harvest Technology and Marketing, Patuakhali Science and Technology University, Patuakhali 8602, Bangladesh

4 Department of Agricultural Economics and Social Sciences, Chattogram Veterinary and Animal Sciences University, Chattogram, Bangladesh

5 Department of Health Sciences, University of Central Florida, Orlando, FL, USA
6 Department of Primary Care \& Mental Health, University of Liverpool, Liverpool, UK

7 Faculty of Nutrition and Food Science, Patuakhali Science and Technology University, Patuakhali 8602, Bangladesh

8 The Research Center for Preclinical Medicine, Southwest Medical University, Luzhou, Sichuan, China

9 IInfectious Diseases Division, International Centre for Diarrhoeal Disease Research, Bangladesh (icddr,b), Dhaka 1212, Bangladesh

10 Department of Emergency Management, Patuakhali Science and Technology University, Patuakhali 8602, Bangladesh

11 Key Laboratory of Mountain Surface Process and Ecological Regulation, Institute of Mountain Hazards and Environment, Chinese Academy of Sciences, Chengdu 610041, Sichuan, China

12 University of Chinese Academy of Sciences, Beijing 100049, China 


\section{Introduction}

The novel coronavirus disease 19 (COVID-19) is a highly transmissible human respiratory disease that infected more than 10 million people and caused approximately 501,000 deaths worldwide as of 1 July 2020 (WHO 2020a). COVID19 is caused by severe acute respiratory syndrome coronavirus 2 (SARS-CoV-2) that first appeared in Wuhan, China (Rothan and Byrareddy 2020; Banna et al. 2020; Kundu et al. 2020). This zoonotic virus can be transmitted by droplets, fecal-oral route, and direct contact, and has an incubation period of 1 to 14 days (Schoeman and Fielding 2019; CDC 2020; Huynh and Nguyen 2020; Li et al. 2020; WHO 2020b), after which, it can cause flu-like symptoms and serious respiratory failure and death. The elderly and those with chronic diseases are at a greater risk of more serious health outcomes (He et al. 2020; Sayeed et al. 2020a; Eurosurveillance Team 2020). Contrarily, individuals who test positive for COVID-19 can show no symptoms and may not be as contagious, limiting their ability to spread the virus (Lauren M. Sauer 2020). Due to these situations, the World Health Organization (WHO) declared COVID-19 as a public health emergency of international concern (PHEIC) (He et al. 2020; Eurosurveillance Team 2020; WHO 2020c) and a "global pandemic" on 11 March 2020 (WHO 2020d).

On 8 March 2020, Bangladesh reported its first COVID-19 case (Anadolu Agency 2020; Sayeed et al. 2020b; WHO 2020e). As part of efforts to contain the outbreak, on 16 March 2020, the Government of Bangladesh closed all educational institutions to contain the COVID-19 outbreak. The government also forbid all public gatherings, announced the closure of public and private offices (WHO 2020f; Begum et al. 2021, kundu et al. 2020), and suspended travel from current countries that were showing the highest number of COVID-19 cases at the time: China, Iran, and Italy (Anadolu Agency 2020). The response of the citizens to these government rules was largely unknown and undocumented and ultimately depends on their attitude and perception of the seriousness of the problem (De La Vega et al. 2020). As of 1 July 2020, COVID 19 confirmed cases in Bangladesh increased to 1,45,484, including 1874 deaths (IEDCR 2020). As there is no current cure or vaccine for the COVID-19 and medical treatments are limited to supportive care (Bhagavathula et al. 2020; Huynh and Nguyen 2020), the WHO has placed an emphasis on prevention. This includes increasing the awareness of the disease and its consequences for health, promoting good personal hygiene practices, and suggesting a positive attitude toward diseased persons, all in an effort to contain the transmission of COVID-19 (WHO 2020g).

In the past, knowledge, attitudes, precautionary behaviors, and active social participation had positive effects on the control of the epidemics of SARS, Ebola, and H1N1 human influenza flu (Bell 2004; Vartti et al. 2009; Dorfan and Woody 2011; Yang and Chu 2018). Knowledge of infection pathways and relevant precautions to take is needed to control the pandemic. Previous studies (Brug et al. 2004; Choi and Yang 2010; Hussain et al. 2012) showed that the knowledge of infectious disease allows the individual to act to prevent infection. To achieve ultimate success against COVID-19 in Bangladesh, people's awareness, healthy practices, and positive commitment are necessary to help contain transmission of the virus, according to KAP theory (Tachfouti et al. 2012; Ajilore et al. 2017). To the best of our knowledge, a limited number of studies have investigated the KAP toward COVID19 among Bangladeshi residents. There is an urgent need to understand the public's awareness, especially the educated and internet experienced Bangladeshis toward COVID-19 at this critical moment, to facilitate its outbreak management as efforts toward a vaccine remain underway. This study aimed to evaluate the knowledge, attitude and practices among the people of Bangladesh during the COVID-19 pandemic.

\section{Methods}

\section{Setting and participants}

A web-based survey using cross-sectional design was conducted from 12-28 April 2020, approximately one week after the lockdown of Bangladesh. Because a community-based national sampling survey was not feasible during this situation, we decided to collect the data online. The authors distributed the survey link in all divisions of Bangladesh via social media using snowball sampling. The authors assumed $50 \%$ desired responses of KAP, $5 \%$ level of significance, and $2.5 \%$ margin of error, the total sample size was 1537 to achieve $80 \%$ power. During the data collection period, we found 1765 participants. All individuals were included in the analysis. The survey targeted responses primarily from individuals 18 years and older. The study sample was drawn from eight Bangladesh divisions (i.e., regions/states) each representing approximately $10.2-16.3 \%$ of the entire sample, except for one division (Sylhet division) (7.3\%).

\section{Procedures}

We developed an anonymous online questionnaire to gather data from respondents, developed using WHO course materials on emerging respiratory viruses, including COVID-19. The study tool was originally written in English and then translated into Bangla by an expert in both languages (WHO, 2020b, 2020h). Prior to data collection, the online questionnaire was piloted in a random sample of users group to identify any problems related to clarity and understanding. The online questionnaire included a short overview of the 
context, purpose, procedures, statements about the voluntary and confidential nature of participant responses, and additional notes to assist with completing the questionnaire. The study was performed following the Helsinki Declaration as revised in 2013. By clicking the link sent to the participants' inbox, the user was automatically directed to the study overview and informed consent page. Consenting participants were required to complete demographic information prior to completing the questionnaire. The study was conducted following the Checklist for Reporting Results of Internet ESurveys (CHERRIES) guidelines.

\section{Contents of the study tool}

The survey instrument was 37-close ended questions and took about 5-7 min to complete. The 37-item questionnaire was split into four sections, including participant demographics (11 items), knowledge about COVID-19 (17 items), attitudes toward COVID-19 (6 items), and practices related to COVID-19 (5 items). These questions were addressed with an additional "I don't know" option on a true/false foundation; 1 point was allocated for the correct answer and 0 points for the incorrect/unknown response. The overall score for knowledge ranged from 0 to 17; the score for attitude ranged from 0 to 6 ; and the score for practice ranged from 0 to 5 . The Cronbach's alpha coefficient of the knowledge questions, questions toward attitude, and questions related to practice were $0.80,0.81$, and 0.79 , respectively, indicating acceptable internal consistency (Taber 2018).

\section{Statistical analysis}

Descriptive analyses (frequency, percent, mean, and standard deviation) were computed in all demographic variables, and for knowledge, attitude, and practices (KAP) toward COVID-19. A one-way analysis of variance (ANOVA) and independent sample t-test were employed for KAP across all demographical variables. Multiple linear regression was used to assess the factors associated with the knowledge scores of COVID-19. Based on the adjusted $\mathrm{R}$ square and Mallow's $\mathrm{C}_{\mathrm{p}}$ criterion, the regression model was selected as the final model. All assumptions were checked regarding linear regression after fitting the model. A binary and multinomial logistic regression model was applied for the practice and attitude domains, respectively, to explore the associated factors. Odds ratio (OR) and $95 \%$ confidence interval (CI) were used to quantify the associations. All analyses were completed using the statistical package SPSS (version 23.0) and SAS (version 9.3). The level of significance was set at $5 \%$ for all analyses.

\section{Results}

Out of 1765 respondents, all the participants were Bangladeshi citizens, $64 \%$ male, with an average age of 24.8 years $(\mathrm{SD}=6.30$, range $18-72$ years). Over half $(54.9 \%)$ of the respondents were between 21 and 25 years of age. Unmarried persons made up over $75 \%$ of participants. Among the online users, $99.2 \%$ knew the mode of transmission, $93.3 \%$ were informed about clinical signs, and $92.5 \%$ agreed with 2-14 days incubation. Regarding minimizing the spread of the virus, $99.2 \%$ of respondents knew that hand hygiene, covering nose and mouth while coughing, avoiding contact with sick persons, and avoiding crowded places can reduce their risk of contracting COVID-19. Also, 99\% of respondents knew that home quarantine is crucial to other's safety (Table 1).

The mean knowledge score was $14.49(\mathrm{SD}=1.8$, range 0 17). This average score indicated that a substantial proportion of respondents was aware of the basic knowledge of COVID19. The overall correct response rate on this knowledge test was $85 \%(14.49 / 17 \times 100)$. Knowledge mean scores were significantly different across all demographical variables except gender. Male ( $85.5 \%$ ), aged between 26 and 30 years old $(83.4 \%)$, masters educated persons $(88.5 \%)$, health professionals $(90.5 \%)$, city area peoples $(86.3 \%)$, and trained respondents $(90.0 \%)$ responded better among the respective categories (Table 2).

Multiple linear regression models were selected by using adjusted R-square $\left(\mathrm{R}_{\mathrm{a}}^{2}\right)(0.62)$ and smallest Mallows $\mathrm{Cp}$ criterion (13.70). Also, normality, independence, homoscedasticity, and linearity satisfied the model. Multiple linear regression analysis revealed that age $\leq 20$ years (vs. $>$ 30 years), $\leq 30,000$ BDT income (vs. > 30,000 BDT), Hindu and others religion (vs. Muslim), secondary education, higher secondary and undergraduate (vs. masters), business, and others (vs. employee) were associated with lower knowledge scores of COVID-19. On the other hand, male (vs. female), scientific features (vs. TV), and training (vs. no training) were associated with higher scores. There was an interaction effect between occupation business (vs. employee) and training (vs. no training) (Table 3).

Just over half $(51.7 \%)$ of the participants have confidence that Bangladesh will win the battle against COVID-19. Similarly, $54.4 \%$ were worried that they and family members could get sick with COVID-19 at any time and did not want any individuals in the community even after they recovered from illness. In addition, $94.1 \%$ of responders thought that social distancing is essential to stop the spread of the virus. All attitudes were significantly associated with different demographic variables. Only gender was not associated with attitudes. The mean knowledge score was significantly different for all attitudes toward COVID-19 (Table 4). 
Table 1 Questionnaire of knowledge, attitudes, and practices toward COVID-19
Options

Knowledge (Correct rate, $\mathrm{n}(\%)$ of the total sample)

K1. COVID-19 is transmitted through sneezing, coughing, and with contact of affected people. $(99.2 \%)$

K2. Headache, fever, cough, sore throat, and flu-like are symptoms of COVID-19. $(93.3 \%)$

K3. COVID-19 symptoms appear in 2-14 days. (92.5\%)

K4. COVID-19 can lead to pneumonia, respiratory failure, and death. (93.9\%)

K5. Supportive care is the current treatment for COVID-19. (76.7\%)

K6. Hand hygiene, covering nose and mouth while coughing, and avoiding sick contacts can help in the prevention of COVID-19 transmission. (99.2\%)

K7. A Flu vaccination is sufficient for preventing COVID-19. (71.6\%)

K8. Eating well-cooked and safely handled meat would result in COVID-19infection. $(74.4 \%)$

K9. Sick patients should share their recent travel history with healthcare providers. $(93.5 \%)$

K10. Disinfect equipment, surfaces, and working areas in markets at least once a day. $(93.3 \%)$

K11. It is not necessary for children and young adults to take measures to prevent the COVID-19 infection. (86.4\%)

K12. To prevent COVID-19 infection, individuals should avoid going to crowded places. $(99.2 \%)$

K13. COVID-19 is caused by a virus called SARS-CoV-2. (29.8\%)

K14. Are antibiotics effective in preventing or treating COVID-19? (55.5\%)

K15. COVID-19 is a contagious disease. (91.8\%)

K16. Hands should be washed with soap for at least 20 s. (98.9\%)

K17. Do you know home quarantine is crucial to save others from COVID-19? $(99.5 \%)$

\section{Attitudes}

A1. Do you have confidence that Bangladesh can win the battle against COVID-19?

A2. Do you think that you and your family may get sick with COVID-19?

A3. Do you think social distancing is essential to stop the spread of the virus?

A4. Would you allow infected individuals into your community after they have recovered from COVID-19, as you did previously?

\section{Practices}

P1. In recent days, have you gone to any crowded place?

P2. In recent days, have you worn a mask when leaving home?

P3. Do you disinfect your hands with soap upon returning from public places?

P4. Do you change your clothes when you come back from public places?

P5. Do you disinfect your hands after sneezing or coughing into your hands?
True, False, I do not Know

True, False, I do not Know

True, False, I do not Know

True, False, I do not Know

True, False, I do not Know

True, False, I do not Know

True, False, I do not Know

True, False, I do not Know

True, False, I do not Know

True, False, I do not Know

True, False, I do not Know

True, False, I do not Know

True, False, I do not Know

Yes, No, I do not Know

True, False, I do not Know

True, False, I do not Know

Yes, No, I do not Know

Yes, No, Do not know

Yes, No, Do not know

Yes, No, Do not know

Yes, No, Do not know

Yes, No

Yes, No

Yes, No

Yes, No

Yes, No
Characteristics of the participants were associated with the attitudes toward the COVID-19. On the contrary, people who received online training were less likely not to win the combat against COVID-19. Unemployed responders and homemakers were more likely to be unsure about the win over COVID-19. In the event of getting ill, older people (age > 
Table 2 Distribution of respondents and "knowledge" scores of COVID-19 across demographics in Bangladesh, $2020(N=1765)$

\begin{tabular}{|c|c|c|c|c|c|}
\hline Parameters & Categories & $\begin{array}{l}\text { Frequency } \\
(\%)\end{array}$ & $\begin{array}{l}\text { Knowledge score } \\
(\operatorname{mean} \pm \text { SD })\end{array}$ & $\mathbf{t} / \mathbf{F}$ & $p$ value \\
\hline Gender & $\begin{array}{l}\text { Male } \\
\text { Female }\end{array}$ & $\begin{array}{r}1129(64.0) \\
636(36.0)\end{array}$ & $\begin{array}{l}14.54 \pm 1.84 \\
14.38 \pm 1.82\end{array}$ & 1.79 & 0.074 \\
\hline Age & $\begin{array}{l}\leq 20 \\
21-25 \\
26-30 \\
\text { Above } 30\end{array}$ & $\begin{array}{l}288(16.3) \\
969(54.9) \\
338(19.2) \\
170(9.6)\end{array}$ & $\begin{array}{l}13.81 \pm 2.12 \\
14.63 \pm 1.55 \\
14.82 \pm 1.77 \\
14.18 \pm 2.51\end{array}$ & 8.33 & $<0.001$ \\
\hline $\begin{array}{l}\text { Monthly income } \\
\text { (BDT) }\end{array}$ & $\begin{array}{l}\leq 30,000 \\
>30,000\end{array}$ & $\begin{array}{l}940(53.3) \\
825(46.7)\end{array}$ & $\begin{array}{l}14.38 \pm 1.79 \\
14.61 \pm 1.88\end{array}$ & 2.71 & 0.007 \\
\hline Religion & $\begin{array}{l}\text { Muslim } \\
\text { Hindu } \\
\text { Others }\end{array}$ & $\begin{array}{c}1380(78.2) \\
373(21.1) \\
12(0.7)\end{array}$ & $\begin{array}{l}14.53 \pm 1.84 \\
14.38 \pm 1.77 \\
12.75 \pm 2.73\end{array}$ & 1.89 & 0.031 \\
\hline Marital status & $\begin{array}{l}\text { Married } \\
\text { Unmarried }\end{array}$ & $\begin{array}{r}384(21.8) \\
1381(78.2)\end{array}$ & $\begin{array}{l}14.45 \pm 2.13 \\
14.50 \pm 1.74\end{array}$ & 1.23 & 0.089 \\
\hline Education status & $\begin{array}{l}\text { Below secondary } \\
\text { High School } \\
\text { College } \\
\text { Honours } \\
\text { Masters or Higher }\end{array}$ & $\begin{array}{c}6(0.3) \\
62(3.5) \\
223(12.6) \\
999(56.6) \\
475(26.9)\end{array}$ & $\begin{aligned} 9.67 & \pm 5.82 \\
11.97 & \pm 2.52 \\
13.90 & \pm 2.14 \\
14.54 & \pm 1.61 \\
15.04 & \pm 1.46\end{aligned}$ & 23.46 & $<0.001$ \\
\hline Occupation & $\begin{array}{l}\text { Student } \\
\text { Health } \\
\quad \text { Professional } \\
\text { Employee } \\
\text { Business } \\
\text { Unemployed } \\
\text { Housewife } \\
\text { Others }\end{array}$ & $\begin{array}{c}937(53.1) \\
118(6.7) \\
352(19.9) \\
40(2.3) \\
184(10.4) \\
68(3.9) \\
66(3.7)\end{array}$ & $\begin{array}{l}14.41 \pm 1.75 \\
15.39 \pm 1.17 \\
14.81 \pm 1.7 \\
13.75 \pm 2.46 \\
14.55 \pm 1.82 \\
13.00 \pm 2.81 \\
14.00 \pm 1.79\end{array}$ & 5.40 & $<0.001$ \\
\hline Residence & $\begin{array}{l}\text { Rural } \\
\text { Semi-urban } \\
\text { Urban }\end{array}$ & $\begin{array}{l}497(28.2) \\
621(35.2) \\
647(36.7)\end{array}$ & $\begin{array}{l}14.23 \pm 2.13 \\
14.49 \pm 1.74 \\
14.68 \pm 1.65\end{array}$ & 3.34 & $<0.001$ \\
\hline Source of information & $\begin{array}{l}\text { Facebook } \\
\text { TV } \\
\text { Newspaper } \\
\text { Scientific features } \\
\text { Others }\end{array}$ & $\begin{array}{c}894(50.7) \\
625(35.4) \\
98(5.6) \\
58(3.3) \\
90(5.1)\end{array}$ & $\begin{array}{l}14.48 \pm 1.70 \\
14.48 \pm 1.83 \\
14.65 \pm 2.05 \\
15.40 \pm 1.12 \\
13.79 \pm 2.81\end{array}$ & 6.84 & $<0.001$ \\
\hline Received training & $\begin{array}{l}\text { Yes } \\
\text { No }\end{array}$ & $\begin{array}{r}260(14.7) \\
1505(85.3)\end{array}$ & $\begin{array}{l}15.30 \pm 1.28 \\
14.34 \pm 1.88\end{array}$ & 7.92 & $<0.001$ \\
\hline
\end{tabular}

30) and television viewers were more likely to disagree about being sick than younger people (age $\leq 20$ ) and individuals who used miscellaneous outlets for details. With respect to social distancing, those who did not receive COVID-19 training were more likely to be unaware of controlling COVID-19. Unmarried persons and television audiences (vs. other sources) were more disagreeable about not allowing people in the community following recovery from the virus. Untrained persons were more confused about allowing the recovered persons back into society (Table 5).

More than $11 \%$ of respondents recently went outside the house. As protective measures, 96.6\% wore masks outside, $98.7 \%$ washed hands with soap, and $82.8 \%$ changed clothing when they returned home. Recently, more than one-third of employed persons went outside, followed by individuals who were aged over 30 years old $(23.5 \%)$, and who were married $(20.6 \%)$, respectively. Approximately $88 \%$ disinfected their hands after sneezing or coughing when they used their hands to cover their mouth. Only high school students comparatively ignored $(67.6 \%)$ the practices. All practices were significantly associated with different demographic variables. The mean knowledge scores were significantly different for the three practices such as wearing a mask when going outside, disinfect hands, and changes clothes after returning from outside (P2, P3, and P4) (Table 6). 
Table 3 Characteristics of respondents associated with COVID-19 "knowledge" score

\begin{tabular}{lrrrr}
\hline Parameters & Estimate & Standard error & t & p value \\
\hline Intercept & 14.903 & 0.109 & $18,715.1$ & $<.0001$ \\
Gender (male vs. female) & 0.169 & 0.086 & 3.85 & 0.049 \\
Age ( $\leq 20$ vs. $>30$ ) & -0.405 & 0.115 & 12.30 & 0.001 \\
Income ( $\leq 30,000$ vs $>30,000)$ & -0.173 & 0.080 & 4.67 & 0.031 \\
Religion (Hindu vs. Muslim) & -0.195 & 0.098 & 3.94 & 0.047 \\
Religion (others vs. Muslim) & -1.357 & 0.487 & 7.78 & 0.005 \\
Education (high school vs. masters) & -2.907 & 0.222 & 170.73 & $<.0001$ \\
Education (college vs. masters) & -0.831 & 0.143 & 33.89 & $<.0001$ \\
Education (honors vs. masters) & -0.375 & 0.097 & 15.11 & 0.0001 \\
Occupation (health professionals vs. employee) & 0.569 & 0.165 & 11.89 & 0.001 \\
Occupation (business vs. employee) & -1.205 & 0.293 & 16.87 & $<.0001$ \\
Occupation (others vs. employee) & -0.436 & 0.214 & 4.14 & 0.042 \\
Source (scientific features vs. TV) & 0.577 & 0.227 & 6.46 & 0.0111 \\
Training (yes vs. no) & 0.566 & 0.120 & 22.29 & $<.0001$ \\
Occupation (business) $\times$ training (yes) & 1.749 & 0.749 & 5.45 & 0.019 \\
\hline
\end{tabular}

Table 7 shows practices toward COVID-19 and associated factors. Based on the average value of respondents (mean, $4.5)$, the practice score was classified as poor or low $(\leq 4.5)$ versus high $(>4.5)$ score. Almost $67.2 \%$ scored high regarding the practices. The goodness of fit for the logistic regression model was $($ Chi-square $=7.49$ and $P=0.481$ ) verified by Hosmer and Lemeshow goodness of fit test. Male (vs. female, OR 3.22, $P<0.001$ ), 26 to 30 age group (vs. above 30 years, OR 1.32, $P=0.027$ ), married person (vs. unmarried, OR 1.58 , $P=0.010$ ), undergraduate students (vs. master's students, OR $1.42, P=0.03$ ), non-employee and housewife (vs. employee, OR 3.38 and $5.07, P=0.002$ and $P=0.001$ ), newspaper readers (vs. TV audiences, OR 1.62, $P=0.009$ ), and COVID-19 knowledge score (OR 0.94, $P=0.003$ ) were significantly associated with low practice scores.

\section{Discussion}

Bangladesh has entered into community transmission phases of the COVID-19 pandemic (Anwar et al. 2020b). People in the community face several challenges during such periods. People should be well aware and practice accordingly to reduce the risk of being infected and transmitting the virus to others. This study first explored the KAP toward COVID-19 among a subpopulation of educated, young adults, and internet experienced people in Bangladesh.

Most of our studied participants (85\%) responded correctly on overall basic knowledge of COVID-19, which was similar to China (90\%) (Zhong et al. 2020), Iran (90\% and $85 \%$ in two knowledge tests) (Erfani et al. 2020), and the USA residents (80\% knowledge scores) (Clements 2020). The small fluctuation may be due to the variation in characteristics of participants such as the highly educated sample (Zhong et al. 2020), and the inclusion of more health-related professionals (Erfani et al. 2020). For instance, we found a $90.5 \%$ correct response rate among health professionals, which was in accordance with the findings from Vietnamese health workers (Huynh and Nguyen 2020). Moreover, types of questions also affect the mean response rate of participants. The rate could be lower for more technical queries. This study showed the lowest correct response rates for K13 (COVID-19 is caused by a virus called SARS-CoV-2) (29.8\%), which decreased the mean rates of correct answers for all queries. A study conducted in India revealed the responders had a moderate level of knowledge on infection, and adequate knowledge about its preventive aspects with the authors stating this is likely due to the government and media emphasizing more preventive measures (Roy et al. 2020). Though there is a lag in the presence of the virus in Bangladesh during the survey, the study participants were educated young adults and internet users, and thus they were in a good position to acquire proper online information early enough about the virus that might be a plausible reason of having high knowledge in our study. Specifically, COVID-19 was first identified near the end of 2019, and this study collected the data during the first two weeks of April 2020. Online users became more aware of the exposure of international media since the start of the outbreak. During the early period of the outbreak, a study about KAP toward COVID-19 among the border population of northern Thailand (Srichan et al. 2020) showed that $73.4 \%$ had poor knowledge of disease prevention and control.

Approximately 36.4 to $56.9 \%$ population was optimistic that Bangladesh would win the fight against COVID-19, where the percent of optimistic people in China $(90.8 \%)$ and health workers in Vietnams (90\%) was quite high (Huynh and 


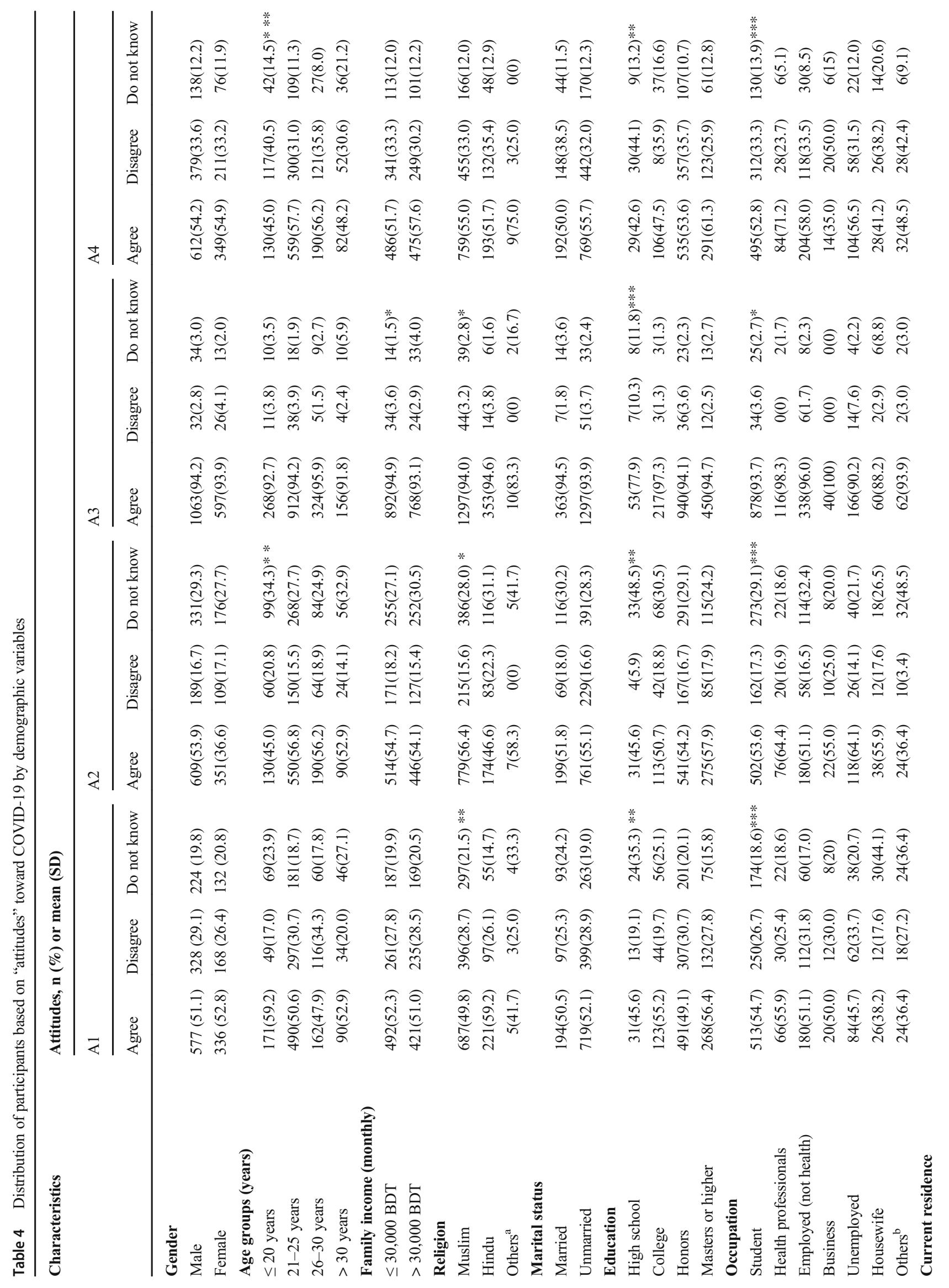




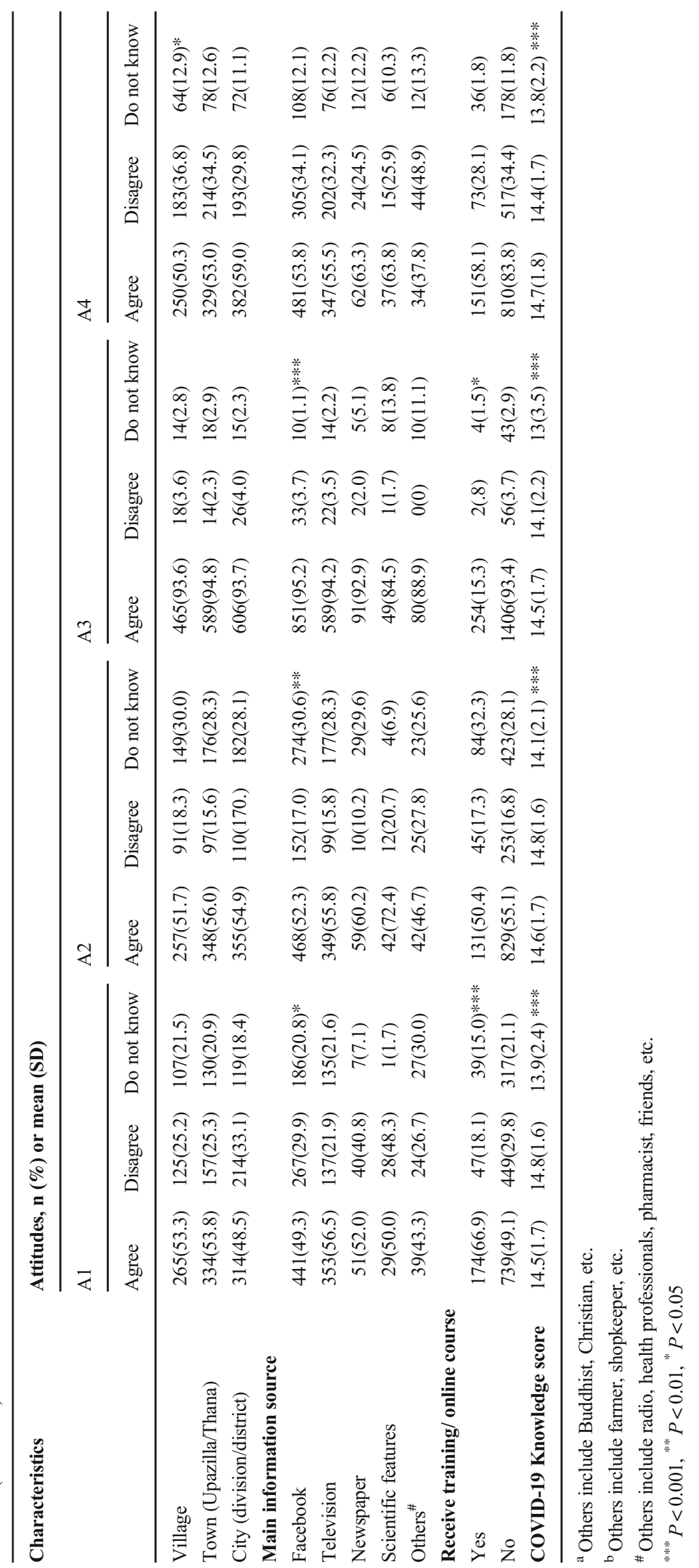


Table 5 Association of demographic variables with "attitudes" toward COVID-19

\begin{tabular}{|c|c|c|}
\hline Parameters & OR $(95 \% \mathrm{CI})$ & $\mathbf{P}$ value \\
\hline \multicolumn{3}{|c|}{ A1: disagree with the win the battle against the COVID-19 (vs. agree) } \\
\hline Age (26-30 vs. >30) & $1.69(1.003,2.86)$ & 0.001 \\
\hline Education (bachelors vs. masters) & $1.70(1.24,2.34)$ & 0.023 \\
\hline Source (scientific features vs. TV) & $3.03(1.65,5.54)$ & 0.029 \\
\hline Training (yes vs. no) & $0.37(0.25,0.53)$ & $<.0001$ \\
\hline Total knowledge score & $0.87(0.79,0.92)$ & 0.0004 \\
\hline \multicolumn{3}{|c|}{ A1: unknown with win the battle against the COVID-19 (vs. agree) } \\
\hline Religion (Hindu vs. Muslim) & $0.59(0.42,0.84)$ & 0.013 \\
\hline Occupation (non-employee vs. employee) & $2.49(1.17,5.29)$ & 0.030 \\
\hline Occupation (housewife vs. employee) & $3.20(1.64,6.23)$ & 0.004 \\
\hline Source (scientific features vs. TV) & $0.10(0.01,0.74)$ & 0.036 \\
\hline Training (yes vs. no) & $0.65(0.44,0.97)$ & 0.024 \\
\hline Total knowledge score & $0.92(0.86,0.99)$ & 0.016 \\
\hline \multicolumn{3}{|l|}{ A2: disagree with getting sick (vs. agree) } \\
\hline Age $(\leq 20$ vs. $>30)$ & $2.87(1.34,6.17)$ & 0.002 \\
\hline Source (others vs. TV) & $2.47(1.38,4.42)$ & 0.002 \\
\hline \multicolumn{3}{|l|}{ A2: unknown about getting sick (vs. agree) } \\
\hline Occupation (non-employee vs. employee) & $0.51(0.32,0.82)$ & 0.206 \\
\hline Source (scientific features vs. TV) & $0.20(0.07,0.57)$ & 0.002 \\
\hline Training (yes vs. no) & $1.67(1.21,2.31)$ & 0.002 \\
\hline Total knowledge score & $0.90(0.84,0.96)$ & 0.001 \\
\hline \multicolumn{3}{|c|}{ A3: disagree with social distancing to control COVID-19 (vs. agree) } \\
\hline Education (secondary vs. masters) & $3.75(1.17,12.01)$ & 0.002 \\
\hline Training (yes vs. no) & $0.21(0.05,0.87)$ & 0.032 \\
\hline \multicolumn{3}{|c|}{ A3: unknown about social distancing to control COVID-19 (vs. agree) } \\
\hline Family income $(\leq 30,000$ vs. $>30,000)$ & $0.33(0.17,0.63)$ & 0.0008 \\
\hline Total knowledge score & $0.76(0.66,0.88)$ & 0.0002 \\
\hline \multicolumn{3}{|c|}{ A4: disagree allowed individual after recovery (vs. agree) } \\
\hline Family income $(\leq 30,000$ vs. $>30,000)$ & $1.28(1.03,1.58)$ & 0.026 \\
\hline Marital status (married vs. unmarried) & $1.61(1.14,2.28)$ & 0.007 \\
\hline source (others vs. TV) & $1.95(1.17,3.24)$ & 0.007 \\
\hline \multicolumn{3}{|c|}{ A4: unknown about allowed individual after recovery (vs. agree) } \\
\hline Age (21-25 vs. >30) & $0.20(0.09,0.42)$ & 0.002 \\
\hline Occupation (student vs. employee) & $3.02(1.60,5.70)$ & 0.007 \\
\hline Training (yes vs. no) & $1.55(1.01,2.38)$ & 0.044 \\
\hline Total knowledge score & $0.78(0.72,0.85)$ & $<.0001$ \\
\hline
\end{tabular}

Nguyen 2020; Zhong et al. 2020). Recently 5.5-35\% of Bangladesh citizens from different demographic groups were going outside, where nearly $96.4 \%$ of China residents avoided crowds during this COVID-19 pandemic (Zhong et al. 2020). Almost everyone (91-100\%) wore masks when they went outside the home except the housewife, with similar results seen in the Chinese population (98\%) (Zhong et al. 2020).

We found gender, family income, educational level, occupation, source of information were associated with the knowledge score toward COVID-19, which is similar to the findings from several studies (Clements 2020; Erfani et al. 2020;
Ferdous et al. 2020; Haque et al. 2020; Zhong et al. 2020). Srichan et al. stated age, but not gender was associated with knowledge in Thailand (Srichan et al. 2020). However, males (compared to females) were found with a higher knowledge score, which is in opposition to a study conducted in China (Zhong et al. 2020). This could be due to the higher participation of males with high education levels in our study, with previous studies reporting the association of education levels (Clements 2020; Erfani et al. 2020; Zhong et al. 2020).

Only half $(51.7 \%)$ of the participants had confidence about Bangladesh's ability to overcome COVID-19, which was less 


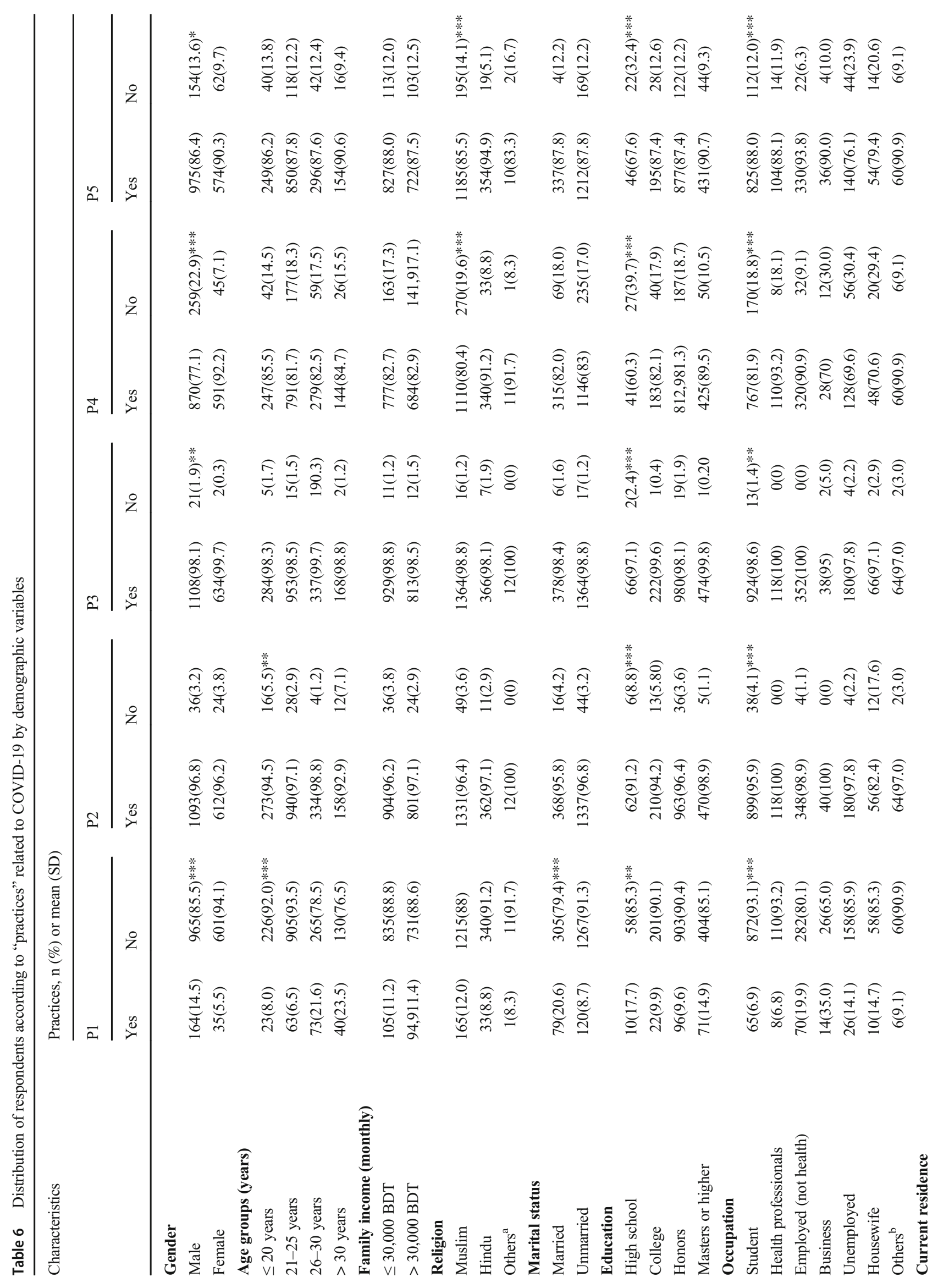




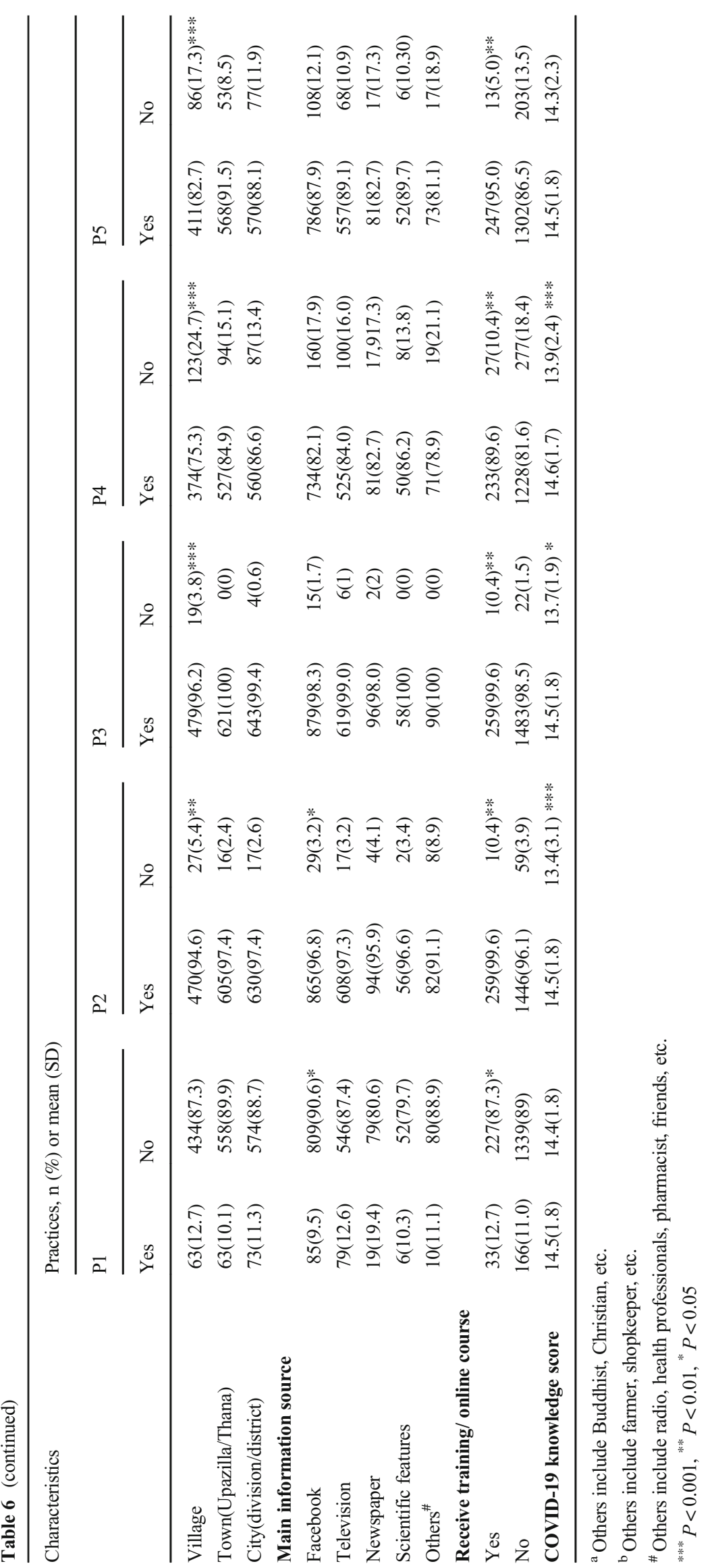


Table 7 Association of demographic variables with COVID-19 related "practices" on COVID-19

\begin{tabular}{lll}
\hline Parameters & OR (95\% CI) & P value \\
\hline Gender (male vs. female) & $3.22(2.46,4.21)$ & $<.0001$ \\
Age (26-30 vs. >30) & $1.32(1.25,1.92)$ & 0.027 \\
Marital status (married vs. unmarried) & $1.58(1.11,2.25)$ & 0.010 \\
Education (bachelors vs. masters) & $1.42(1.05,1.92)$ & 0.031 \\
Occupation (non-employee vs. employee) & $3.38(2.20,5.20)$ & 0.002 \\
Occupation (housewife vs. employee) & $5.07(2.64,9.72)$ & 0.001 \\
Source (newspaper vs. TV) & $1.62(1.03,2.56)$ & 0.009 \\
Training (yes vs. no) & $0.59(0.42,0.83)$ & 0.002 \\
Total knowledge score & $0.94(0.87-0.98)$ & 0.003 \\
\hline
\end{tabular}

than China (97.1\%) (Zhong et al. 2020). This pessimistic response may be due to poor health care and quarantine facilities in Bangladesh. Furthermore, Bangladeshi citizens' negative mindset may be related to inadequate health care services, low COVID-19 testing rates, and lower economic conditions. On the other hand, the optimistic attitude of the Chinese residents could be related to the unprecedented COVID-19 control measures such as traffic limits and shutdowns in critical areas and available medical workers and materials in highly impacted areas (Zhong et al. 2020).

Almost half of the respondents were afraid of getting the virus at any time. This fear could be due to the apparent failures regarding the successful management of the pandemic (e.g., lack of appropriate and widespread testing facilities, shortage of PPE, etc.). In addition, Bangladesh citizens who were traveling abroad during the early stage of the pandemic neglected the home quarantine system and accelerated the outbreak. Also, the high density of the population makes it almost impossible to maintain social distancing in the food and medicine markets, which remained, and still remain, open during the shutdown period. Due to economic deprivation, many people in Bangladesh are being forced to go outside to get food. Approximately $80 \%$ of the health workers in Vietnam were afraid of getting sick at any time, this could be due to their thought of more proximity of health care professionals to the patients and closeness of study setting to COVID-19 origin country China (Huynh and Nguyen 2020). More than half of our respondents denied accepting a previously infected person back into the community. This may be due to high levels of fear of becoming infected. Roy et al. reported that fear and stigma were associated with the return of recovered COVID-19 patients into mainstream society in India (Roy et al. 2020). Authorities are now simultaneously working on these social disparities. Adequate awareness may minimize the stigma and facilitate acceptance in the general population.
Most participants (94.1\%) reported that social distancing is essential to stop the spreading of the virus. This could be due to the government and media emphasizing more preventive measures (Roy et al. 2020). In addition, knowledge regarding the high infectivity and transmission possibilities via invisible respiratory droplets places a lot of importance on physical distancing (Zhong et al. 2020). These positive attitudes should be key measures for effective management of COVID-19, especially in highly populated and low-health care-resourced countries such as Bangladesh.

Our study found considerably positive practices toward COVID-19, which was supported by previous research on COVID-19 in China (Zhong et al. 2020) and on SARS in China (JIAO et al. 2005; Zhong et al. 2020). Most of the people took preventive measures against this infectious disease, such as refraining from public gatherings, wearing masks while going out, and disinfecting their hands upon coming back from outside or public excursions. People following these preventive practices may be due to the swift preventive and control measures taken by the local government, such as prohibiting public gatherings closing all educational institutions, and eventually locking down the whole country (WHO 2020f). In addition, following preventive practices could be a result of people's higher levels of knowledge about the infective nature of COVID-19. The present findings still showed that recently $11.27 \%$ of people went to crowded places, which is much higher than in China (3.6\%) (Zhong et al. 2020), and when outside, $3.4 \%$ of people did not wear masks. This discrepancy from other countries such as China may be due to the socio-economic conditions of both settings. Poor economic structures may force certain individuals to go outside as they have no other option to be physically separated from one another. This study also reported $12.2 \%$ did not sanitize their hands after sneezing or coughing or did not cover their mouth. Moreover, our study findings revealed that $1.3 \%$ and $17.2 \%$ did not disinfect their hands with soap and change clothes after returning from the outside, respectively. These unfavorable and poor practices were mainly related to males 26 to 30 years of age, married persons, unemployed persons, housewives, undergraduate students, those taking newspaper as a source of information, trained persons, and poor COVID19 knowledge.

This study found that males were more likely to have a lower score of practices toward COVID-19 as compared to females, which is similar to a previous study conducted in China (Zhong et al. 2020). Earlier studies on age and gender variations of risk-taking behaviors reported male and late adolescents are more likely to be involved in risk-taking behaviors (Pawlowski et al. 2008; Cobey et al. 2013; Duell et al. 2018). This might be a plausible explanation of poor practices toward COVID-19 among males in this study. The study showed a higher risk of developing poor practices toward this infection among the 26-30 age group (vs. > 30 years) and 
married (vs. unmarried), which might be due to their responsibilities to family members, children, and peers. Undergraduate students were more susceptible to undesired practices toward COVID-19 that could be important in the perspective of prevention management than that of masters' students; however, these risky practices might be due to their younger age. The higher odds of developing poor practices were found to be associated with the occupation of unemployment and housewife (vs. employment) and this finding is in line with the previous Bangladeshi study that assessed KAP toward COVID-19 among women (Anwar et al. 2020a). Because most of the housewives in Bangladesh are underprivileged and disadvantaged due to cultural norms and values, they might be more unaware (Asaduzzaman et al. 2015). In addition, most of the time, they are busy with household works that may hinder them to be updated via mass media and online platforms. Contrarily, unemployed individuals need to go outside as a means of livelihood, which might be resulting in these lower levels of practices. The risk of having a low score of practices was found to be higher among people who obtained information on COVID-19 from newspaper rather than television, as television is an effective learning and reliable medium for all kinds of information, which might be resulting knowledge into behaviors. It is worth mentioning that higher knowledge scores on COVID-19 were found to be significantly associated with a higher likelihood of positive practices toward the COVID-19 epidemic in this study area.

\section{Limitations}

To be noted, this study mostly includes the highly qualified participants in this setting, as over three-fourth of our responders had at least graduated from university. These results may only represent the higher-educated young adult individuals of Bangladesh. Therefore, they cannot be generalized to the whole population. Given the poor economic and educational profiles of this population, and previous findings of poor knowledge and attitudes toward disease prevention in a similar setting (Srichan et al. 2020), a community-based study may represent more accurate results for this area. Finally, we did not explore the causality of going outside for some specific groups (which may have been necessary), which could affect the quarantine campaign for the prevention of COVID-19.

\section{Conclusion}

Our study revealed that a higher knowledge score regarding COVID-19 was significantly associated with a higher likelihood of having a positive attitude and good practices during the COVID-19 pandemic. The attitudes of the participants are moderate, but appropriate and hygienic practices are lacking to control the outbreak, despite a reasonable understanding of COVID-19. The people of Bangladesh are very reluctant to follow government instructions such as improvement of personal hygiene and avoiding unnecessary movement. Considering the current COVID-19 situation, where the number of COVID-19 cases and deaths are increasing day by day, the government should extend and strengthen lockdown to reduce the unnecessary movements of people. Another issue is the potential stigma of the integration of recovered COVID-19 patients into the mainstream of society. Nearly one-third of all respondents and more than $40 \%$ of young and low-educated participants disagreed with allowing recovering patients to rejoin their communities. This implicates a higher level of fear among the community about the COVID-19 outbreak. The government should actively prevent stigmatization and discrimination against recovered COVID-19 patients. Mass awareness campaigns that target specific demographic groups such as housewives, youth, and people with less education may also change the attitudes and practices toward COVID-19. This study provides early evidence in understanding the knowledge, attitude, and practices of the public being online approachable during the pandemic in Bangladesh.

Acknowledgements The authors would like to thank the participants.

Author's contributions Satyajit Kundu: Conceptualization, formal analysis, writing - original draft, validation; Md. Hasan Al Banna: Conceptualization, data curation, writing - original draft; validation; Abu Sayeed: Conceptualization, methodology, writing - original draft, validation; Musammet Rasheda Begum: Formal analysis, software; Keith Brazendale: Writing - review \& editing, visualization; validation; M. Tasdik Hasan: Writing - review \& editing, visualization; Sanjida Jahan Habiba: Data curation and writing; Mohammad Tazrian Abid: Data curation and writing; Md. Asaduzzaman Khan: Data curation and writing; Sukanta Chowdhury: Writing - review and editing, visualization; Tapos Kormoker: Writing - review \& editing; Ram Proshad: Data curation and writing; Md Shafiqul Islam Khan: Investigation, supervision, writing - review \& editing, visualization, validation.

Availability of data and material The data underlying this article will be shared on reasonable request to the corresponding author.

Code availability SPSS/SAS code is available upon request.

\section{Declarations}

Conflict of interest The authors have no conflicts of interest to declare that are relevant to the content of this study.

Ethics approval The study was performed in line with the principles of the declaration of Helsinki and followed the Checklist for Reporting Results of Internet E-Surveys (CHERRIES) guidelines. The research protocol was reviewed and approved by the Research Ethical Committee (REC) of the Department of Food Microbiology, Patuakhali Science and Technology University, Bangladesh (Approval no: FMB:29/03/ 2020:01). 
Consent to participate Informed consent was obtained from all individual participants included in the study.

Consent for publication The participants have consented to the submission of the study to the journal.

\section{References}

Ajilore K, Atakiti I, Onyenankeya K (2017) College students' knowledge, attitudes and adherence to public service announcements on Ebola in Nigeria: suggestions for improving future Ebola prevention education programmes. Health Educ J 76:648-660

Anadolu Agency (2020) Bangladesh confirms first case of coronavirus. https:/www.aa.com.tr/en/asia-pacific/bangladesh-confirms-firstcase-of-coronavirus-/1758924. Accessed 16 Apr 2020

Anwar S, Araf Y, Khan AN, et al (2020a) Women's Knowledge, Attitude, and Perceptions Toward COVID-19 in Lower-MiddleIncome Countries: A Representative Cross-Sectional Study in Bangladesh. Front Public Heal 8

Anwar S, Nasrullah M, Hosen MJ (2020b) COVID-19 and Bangladesh: Challenges and how to address them. Front Public Healh 8:571689. https://doi.org/10.3389/fpubh.2020.571689

Asaduzzaman M, Kabir RNA, Radović-Marković M (2015) Gender inequality in Bangladesh. JWEE 3-4:54-64

Banna, MH Al, Sayeed A, Kundu S, et al (2020) The impact of the COVID-19 pandemic on the mental health of the adult population in Bangladesh: a nationwide cross-sectional study. Int J Environ Health Res 113:613-617. https://doi.org/10.1093/qjmed/hcaa207

Begum MR, Khan MSI, Sayeed A, et al (2021) Mental health difficulties of adults with COVID-19-like symptoms in Bangladesh: a crosssectional correlational study. J Affect Disord Rep 4:100103. https:// doi.org/10.1016/j.jadr.2021.100103

Bell DM, World Health Organization Working Group (2004) Prevention of international and community transmission of SARS spread, 2003. Emerg Infect Dis 10:1900-1906. https://doi.org/10.3201/eid1011. 040729

Bhagavathula AS, Aldhaleei WA, Rahmani J, et al (2020) Novel coronavirus (COVID-19) knowledge and perceptions: a survey on healthcare workers. medRxiv. https://doi.org/10.1101/2020.03.09. 20033381

Brug J, Aro AR, Oenema A et al (2004) SARS risk perception, knowledge, precautions, and information sources, the Netherlands. Emerg Infect Dis 10:1486

CDC (2020) Coronavirus disease 2019 (COVID-19). https://www.cdc. gov/coronavirus/2019-ncov/prevent-getting-sick/how-covidspreads.html?CDC_AA_refVal=https $\% 3 \mathrm{~A} \% 2 \mathrm{~F} \% 2 \mathrm{Fwww} . c d c$. gov $\% 2$ Fcoronavirus $\% 2 \mathrm{~F} 2019$-ncov\% 2 Fprepare $\% 2$ Ftransmission. html. Accessed 16 Apr 2020

Choi J-S, Yang N-Y (2010) Perceived knowledge, attitude, and compliance with preventive behavior on influenza a (H1N1) by university students. Korean J Adult Nurs 22:250-259

Clements JM (2020) Knowledge and behaviors toward COVID-19 among US residents during the early days of the pandemic. medRxiv. https://doi.org/10.1101/2020.03.31.20048967

Cobey KD, Laan F, Stulp G et al (2013) Sex differences in risk taking behavior among Dutch cyclists. Evol Psychol 11: 147470491301100200

De La Vega R, Barquín RR, Boros S, Szabo A (2020) Could attitudes toward COVID-19 in Spain render men more vulnerable than women? Glob Public Health. 15:1278-1291. https://doi.org/10.1080/ 17441692.2020.1791212
Dorfan NM, Woody SR (2011) Danger appraisals as prospective predictors of disgust and avoidance of contaminants. J Soc Clin Psychol $30: 105-132$

Duell N, Steinberg L, Icenogle G et al (2018) Age patterns in risk taking across the world. J Youth Adolesc 47:1052-1072

Erfani A, Shahriarirad R, Ranjbar K, et al (2020) Knowledge, attitude and practice toward the novel coronavirus (COVID-19) outbreak: a population-based survey in Iran. Bull World Heal Organ. https:// www.who.int/bulletin/online_first/20-256651.pdf

Eurosurveillance Team (2020) Note from the editors: World Health Organization declares novel coronavirus (2019-nCoV) sixth public health emergency of international concern. Euro Surveill 25: 200131e

Ferdous MZ, Islam MS, Sikder MT et al (2020) Knowledge, attitude, and practice regarding COVID-19 outbreak in Bangladesh: an onlinebased cross-sectional study. PLoS One 15:e0239254

Haque T, Hossain KM, Bhuiyan MMR, et al (2020) Knowledge, attitude and practices (KAP) towards COVID-19 and assessment of risks of infection by SARS-CoV-2 among the Bangladeshi population: an online cross sectional survey. Res Sq. https://doi.org/10.21203/rs.3. rs-24562/v1

He F, Deng Y, Li W (2020) Coronavirüs disease 2019: What we know. J Med Virol. https://doi.org/10.1002/jmv.25766

Hussain ZA, Hussain SA, Hussain FA (2012) Medical students' knowledge, perceptions, and behavioral intentions towards the H1N1 influenza, swine flu, in Pakistan: a brief report. Am J Infect Control 40:e11-e13

Huynh G, Nguyen TNH (2020) Knowledge and attitude toward COVID19 among healthcare workers at District 2 Hospital, Ho Chi Minh City. Asian Pac J Trop Dis 13:260-265

IEDCR (2020) Covid-19 Status Bangladesh. https://www.iedcr.gov.bd/. Accessed 16 Apr 2020

Jiao J, Tang X, Li H (2005) Survey of knowledge of villagers in prevention and control of SARS in Hainan Province. China Trop Med 4

Kundu S, Banna, MH Al, Sayeed A, et al (2020) Determinants of household food security and dietary diversity during the COVID-19 pandemic in Bangladesh. Public Health Nutr 24:1079-1087. https://doi. org/10.1017/S1368980020005042

Lauren M. Sauer (2020) What Is Coronavirus? https://www. hopkinsmedicine.org/health/conditions-and-diseases/coronavirus.

Li Q, Guan X, Wu P, et al (2020) Early transmission dynamics in Wuhan, China, of novel coronavirus-infected pneumonia. N Engl J Med 382:119-1207

Pawlowski B, Atwal R, Dunbar RIM (2008) Sex differences in everyday risk-taking behavior in humans. Evol Psychol 6: 147470490800600100

Rothan HA, Byrareddy SN (2020) The epidemiology and pathogenesis of coronavirus disease (COVID-19) outbreak. J Autoimmun 109: 102433

Roy D, Tripathy S, Kar SK, et al (2020) Study of knowledge, attitude, anxiety \& perceived mental healthcare need in Indian population during COVID-19 pandemic. Asian J Psychiatr 51:102083

Sayeed A, Kundu S, Al Banna MH et al (2020a) Mental health outcomes of adults with comorbidity and chronic diseases during the COVID19 pandemic: a matched case-control study. Psychiatr Danub 32: 491-498

Sayeed A, Kundu S, Al Banna MH et al (2020b) Mental health outcomes during the COVID-19 and perceptions towards the pandemic: findings from a cross sectional study among Bangladeshi students. Child Youth Serv Rev 119:105658

Schoeman D, Fielding BC (2019) Coronavirus envelope protein: current knowledge. Virol J 16:69

Srichan P, Apidechkul T, Tamornpark R, et al (2020) Knowledge, attitude and preparedness to respond to the 2019 novel coronavirus (COVID-19) among the bordered population of Northern Thailand 
in the early period of the outbreak: a cross-sectional study. http:// dx.doi.org/10.2139/ssrn. 3546046

Taber KS (2018) The use of Cronbach's alpha when developing and reporting research instruments in science education. Res Sci Educ 48:1273-1296

Tachfouti N, Slama K, Berraho M, Nejjari C (2012) The impact of knowledge and attitudes on adherence to tuberculosis treatment: a casecontrol study in a Moroccan region. Pan Afr Med J 12:52

Vartti A-M, Oenema A, Schreck M et al (2009) SARS knowledge, perceptions, and behaviors: a comparison between Finns and the Dutch during the SARS outbreak in 2003. Int J Behav Med 16:41

WHO (2020a) Coronavirus disease 2019 (COVID-19) Situation Report 85. https://www.who.int/emergencies/diseases/novel-coronavirus2019/situation-reports/

WHO (2020b) World health organization. Emerging respiratory viruses, including COVID-19: methods for detection, prevention, response, and control. Available online: https://openwho.org/courses/ introduction-to-ncov

WHO (2020c) WHO director-General's opening remarks at the media briefing on COVID-19 11 March 2020. Switzerland, Geneva. https://www.who.int/director-general/speeches/detail/who-directorgeneral-s-opening-remarks-at-the-media-briefing-on-covid-1911-march-2020

WHO (2020d) WHO announces COVID-19 outbreak a pandemic. http:// www.euro.who.int/en/health-topics/health-emergencies/ coronavirus-covid-19/news/news/2020/3/who-announces-covid19-outbreak-a-pandemic. Accessed 15 Apr 2020

WHO (2020e) Bangladesh Covid-19 Situation Report No. 7. https:// www.who.int/bangladesh/emergencies/coronavirus-disease-(covid19)-update/coronavirus-disease-(covid-2019)-bangladesh-situationreports

WHO (2020f) Bangladesh Covid-19 Situation Report No. 4. https:// www.who.int/bangladesh/emergencies/coronavirus-disease-(covid19)-update/coronavirus-disease-(covid-2019)-bangladesh-situationreports

WHO (2020g) Coronavirus disease (COVID-19) advice for the public. https://www.who.int/emergencies/diseases/novel-coronavirus2019/advice-for-public. Accessed 17 Apr 2020

WHO (2020h) WHO. Q\&A on coronaviruses (COVID-19). 2020. Available from: https:/www.who.int/news-room/q-a-detail/q-acoronaviruses [Accessed on 1st March 2020]

Yang JZ, Chu H (2018) Who is afraid of the Ebola outbreak? The influence of discrete emotions on risk perception. J Risk Res 21:834-853

Zhong B-L, Luo W, Li H-M et al (2020) Knowledge, attitudes, and practices towards COVID-19 among Chinese residents during the rapid rise period of the COVID-19 outbreak: a quick online crosssectional survey. Int J Biol Sci 16:1745

Publisher's note Springer Nature remains neutral with regard to jurisdictional claims in published maps and institutional affiliations. 